\title{
The attitude of foreign language learners on nonverbal communication and privacy in communicative classes
}

\author{
Azedah Nemati \\ Islamic Azad University, Iran \\ azadehnematiar@yahoo.com
}

\begin{abstract}
Communication has verbal and nonverbal aspects. It has been estimated that $82 \%$ of class communication is nonverbal. While the role of nonverbal behavior in English classes is much it is hitherto an unexplored area. One subpart of nonverbal communication is proxemics or space. Combing nonverbal communication and the right to privacy, this article is aimed at exploring the attitude of foreign language students regarding nonverbal communication and privacy right in English classes. A nonverbal questionnaire along with privacy proposed by the researcher was answered by 107 general English participants. Based on their opinion the major findings were that students like, smiling, tidy and on time teachers who explain and illustrate in English classes. However, they do not like to answer questions regarding their personal life such as personal description, identification, health or background. As a result, their privacy right should be observed in communicative English classes.
\end{abstract}

\section{ARTICLE HISTORY}

Received 19 February 2019 Accepted 30 April 2019

\section{KEYWORDS}

Communicative class; nonverbal communication; privacy; attitude

\section{Introduction}

Communication is a significant method in our lives and hence in the lives of our learners. In general, verbal communication is a codified system that is learned fluently, perhaps because teaching, understanding and memorizing are simpler (Mainez, 2017).

There is a common sense in the literature for the definition of communication. In general, communication refers to The process of sending and receiving messages that allow people to share the attitude and feelings of information (Elfatihi, 2006); Negi, 2010). Although communication is connected with speech, it consists of two aspects, verbal and nonverbal communication.

As stated by Bugoon, et al.(1990) verbal communication (VC) is spoken or written form of communication produced intentionally for obvious reason and is highly structured. Unlike VC, non-verbal communication (NVC) is often described 
without a word as communication. NVC is more universal and culture-specific. The smile would be a good example of the universality of NVC. Everything communicates including what the people wear, Their voice pitch and tone, and the manner they handle their bodies, the way they seat or even stand (Elfatihi, 2006;Batmang, Gunawan, Abdul Samad, \& Shamsuri Md Saad, 2018) said that $60 \%$ of our social meaning is through NVC (Hall, 1959). Even some researchers like Neulieo (2003) postulated that as much as $90 \%$ of all communications are nonverbal. In the classroom also It is estimated that up to 82 percent of teachers ' communication techniques are nonverbal (Kellog \& Lawson, 1993). Therefore, the concept that communication breaks are no longer applicable when a individual keeps silent. Thus, if NVC uses silence properly, it can be a ideal means of communication (Development, 2006).

Just as language NVC is also large and complicated to categorize its components. However, A tentative classification of the main parts for the sake of clarity used in this study is presented as follows. This classification is more or less presented and defined by others such as Dam (2005)and Allen (2000) to name but a few.

Kinesics and gesture: body movement, Posture: position and orientation of the body, Facial expression: gesture produced by the muscles of the face, Ocuesics: use of eye contact, Proxemics (with it two subparts of space and privacy): space management in relation to social and physical environment,Vocalic: tone, pitch, volume and speed of voice, Chronemics: time management, Clothing, and jewelry: or adornment is clothes, jewelry and hairstyle, Haptics: use of touch, Olfactics: use of smell.

As stated above, proxemics is the study of personal distance. As categorized by Hall(1959)there are four distances as touching to 18 inches, between 18 and 4 feet, between 4 and 12 feet and lastly 12 feet meaning intimate, personal, causal and public relationship respectively. While this distance is physical, another aspect to distance was added in this study and that is privacy or invisible bubble.

If human beings do possess different rights, students also should have. If people have a right to privacy, then students also have that right. (Davis, 2001). An increasing body of legislation provisions and standards requires that the privacy and confidentiality of information about students, employers, patients, consumers, citizens, and others be protected and secured (Warkentin, et al. (2011). Much of what is said about privacy right is characterized in discourse (ibid). Right is about the way people ought to treat each other hence as stated by Davis (2001)other terms such as duty, obligation, ought and must be used. The same situation is met in classrooms and also English classes. English courses do not have enforced privacy rights.

The privacy right in this article is after Davis (2001, p. 246) and is defined in the sense that "Others have a obligation not to access or attempt to access private aspects of others." Some anthropologist (such as Westin, 1984) believed that privacy is culture-specific. Since the focus of this article is on students here an example from education regarding privacy right is brought from Davis (2001, p. 247). He discussed that privacy is violated in the following educational example: 
Schoolchildren are often asked to discuss their families or build family trees. They may not want to disclose such details to the teacher or the class, however. Children may have a wide range of reasons for their reservation depending on their social and cultural context.

Even the concept of online privacy issue was proposed by Johns \& Lawson (2005). They surveyed 444 learners at Iowa State University who needed library orientation classes to enroll in the university. The authors examined the knowledge and perception of the students regarding the issue of online privacy, their opinion on who should collect their private information, for what purpose and under what circumstances.

The same situation is met in English classes. They are not appropriate topics to ask about religious, cultural or political belief, or questions that require learners to express their feeling thought or ideas about personal matters in public.

\section{Review of literature}

Communication is more than expressing ideas and feeling by means of a word only. Nonverbal communication from the moment we enter the world is a basic element of human existence (Negi, 2009). Each researcher worked on one aspect of NVC. Christopher(2002) found out that Males exhibit more active conduct compared to women. Leathers (1997) classified facial expressions. Kusanagi (2004) attempted to present an overview of the top 27 articles investigating NVC. Argyle (1988) proposes 16 types of touching. Davis (2001) asked this question in his article: Do kids have the right to privacy in school? In his article, he discussed that kids have the right to privacy in the classroom and persuade the teacher to observe this right.

Poyatos (2002) explained different eye contacts and gazes such as downward glances which are associated with modesty, wide eyes with frankness, wonder or terror. Elfatihi, (2006) wrote his dissertation on the role of NVC in beginners' EFL classrooms and probed different media of NVC. Hassan (2007) worked on NVC and colleague students. Francisca \& Santos(n.d.), as well as Gregersen (2007), asserted that teachers nonverbal sign tends to explain or monitor their verbal behavior.

Negi (2009) wrote an article regarding The role of NVC educators in the courses of ELT. He concluded that NVC plays a very significant and vital role in the language classroom motivation of learners. Mata (2010)wrote an article and analyzed the psychological dimensions of private life and its relation to school success. Kruger (2009) did a pilot study on NVC in the foreign language classroom. He first gave an overview of what constitutes nonverbal communication, followed by a pilot research to explore the impacts of visual signals on the listening understanding of EFL learners. Finally, he found that the use of gesture in the EFL classroom and listening comprehension have a favorable connection. 
Nobrega (2012) discussed the importance of students' spontaneous smile in EFL classroom interaction. The researcher concluded that students' spontaneous smile appeared to be a nonverbal indicative of proximity and increased oral interaction among them.Karimi, M., Dabaghi, A., \& Tabatabai (2012) investigated the effect of teaching gesture to the experimental group. They concluded that the students of the experimental group outperformed the students of control in understanding lexical items. Safarali Karbalai, S., \& Hamidi (2012) explored the efficacy of video showing the gesture of speakers and facial clues on the listening comprehension of Iranian EFL learners.Batmang and colleagues (2018) Batmang carried out studies to explore the language style of lecturers and their implications for the psychological situation of the student in Indonesia. What kind of language style the lecturer used in the teaching process was the primary issue in this studies? Has the use of language style of lecturers influenced the psychological situation of learners? What were the variables affecting the language style of lecturers?

While most of the researchers focused on the verbal aspect of communication a few researchers worked on NVC and very few on the privacy right of pupils and none worked on NVC as well as privacy right as a subpart of proxemics in EFL classes.

\section{Objectives of the study}

Though more than half of the meaning is conveyed nonverbally, the research of NVC in the field of teaching and learning has long been overlooked. As communication was the main focus of learning English with the advent of language teaching in the seventies and early eighties, the study of NVC as well seems crucial. Thus, the aim of this study is two-fold. Firstly, it aims at clarifying the usefulness and effects of NVC in foreign language classes such as general English class in this case from the point of view of students. Secondly, it is intended to address the privacy right of students in communicative English classes in front of other students. In other words, it asks the extent to which English students will enjoy a right to privacy in English classes based on their opinion.

\section{Research questions}

This study seeks an answer to the following questions:

1) What is the attitude of general English students regarding nonverbal communication in communicative classes?

2) What is the attitude of students regarding privacy and asking private questions in communicative classes? 


\section{Methodology}

\section{Participants}

This study was realized in 107 general English students of different majors. They were selected based on convenient/availability method since they had a general English class with the researcher.From this population 53 of them were male and 64 of them were female ( 45.3 percent vs. 54.7). Their age range was from 17 to 47 with the mean of 22.62 and standard deviation of 4.48 .

\section{Instrument and procedure}

This study proceeds to apply one yes/no questionnaire devised by the researcher. The instrument consisted of 85 questions with 19 subparts about nonverbal communication and privacy. Of the total questions 31 questions were about privacy and were made by the researcher.Whereas,54 other questions regarding nonverbal communication, adapted and adopted from other questionnaires such as Elfatihi(2006) and Negi, 2009(Appendix I).

The students were asked to fill the form and give their ideas by answering "yes", "no" or "no idea"for most of the questions in one session of their general English class. The final goal of general English class is communication. The participants of different majors should first pass "Basic English" then "General English". It is for 3 credits per week, means that the participants have 3-hour English class each week.

\section{Results and discussions}

After collecting the data through a questionnaire they were coded, analyzed and interpreted qualitatively. The results are presented through tables and graphs in this part.

Table 1. percentages of answers to nonverbal communication questions

\begin{tabular}{clll}
\hline \multicolumn{3}{c}{ Percent } & \\
\hline $\begin{array}{c}\text { Nonverbal } \\
\text { communication }\end{array}$ & Yes & No & No Idea \\
\hline Kinesics & 90.9 & 1.0 & 8.1 \\
\hline Postures & 96.2 & 2.9 & 5.4 \\
\hline Facial expression & 73.0 & 21.6 & 1.0 \\
\hline Oculesics & 78.7 & 1.0 & 20.3 \\
\hline Space & 82.1 & 9.0 & 83.0 \\
\hline Vocalic & 43.2 & 28.8 & 27.9 \\
\hline
\end{tabular}




\begin{tabular}{llll}
\hline Chronemics & 93.7 & 0.9 & 5.4 \\
\hline Clothing/ jewelry & 70.0 & 15.5 & 14.5 \\
\hline Haptics & 34.8 & 33.9 & 31.3 \\
\hline Olfactics & 81.0 & 6.9 & 12.1 \\
\hline
\end{tabular}

Table 1 revealed the result of nonverbal questions. The first part of the questionnaire was about kinesics. In the literature, kinesics is about body movement and gesture. The result showed that 90.9 percent of the participants believe that teacher's gesture will help them understand English better, and they like teachers to illustrate the subject matter as well as to explain the points for them.In response to question number 3,most of the participants $(74.1 \%)$ expressed that when teacher use gesture while teaching the lessons stick in their mind for a longer time. While 59.5\% mentioned that moving in class does not distract their attention.

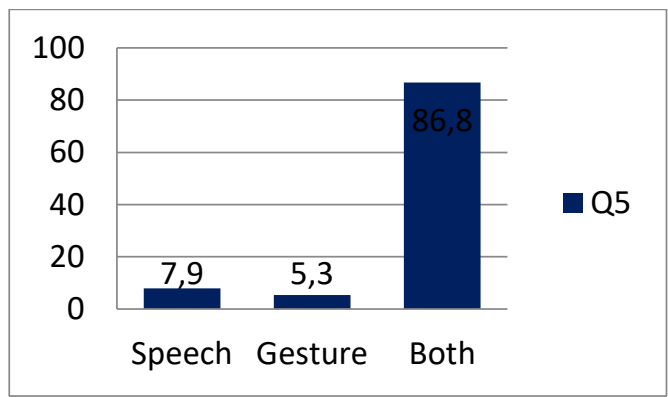

Figure 1. What should the teacher use when explaining?

In addition, asking "what should the teacher use when explaining the points "Figure 1 showed that 86.8 percent of the students stated that they like teachers use both gesture and speech. This question also supports the idea that gesture will help them understand better in class.

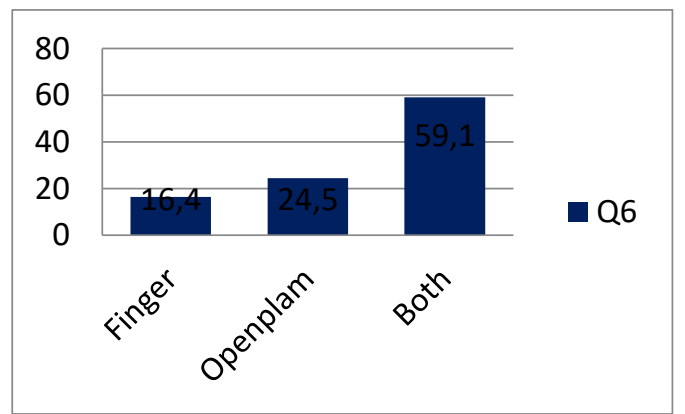

Figure 2. What should the teacher use to point to you?

The majority of the participants along with English teachers use both fingers and open palm when calling them in class. Just 16.4 of them like English teachers call them in class using a finger. 
The second part of the questionnaire was about posture. Of the whole participants, 73 percent of them agree with the idea that when teachers lean against a wall or cross their arms it is disgusting for them. They like teachers to encourage the students by nodding the head. Also, they believed that the friendly style and personality of the teacher is a contributing factor to their learning.

Facial expression was another medium of nonverbal communication in effective classroom interaction. Nearly all the students (96.2\%) love a smiling teacher who laughs and tells a joke in class. The students and their classmates did not like fatigue and exhausted teacher who is always serious.

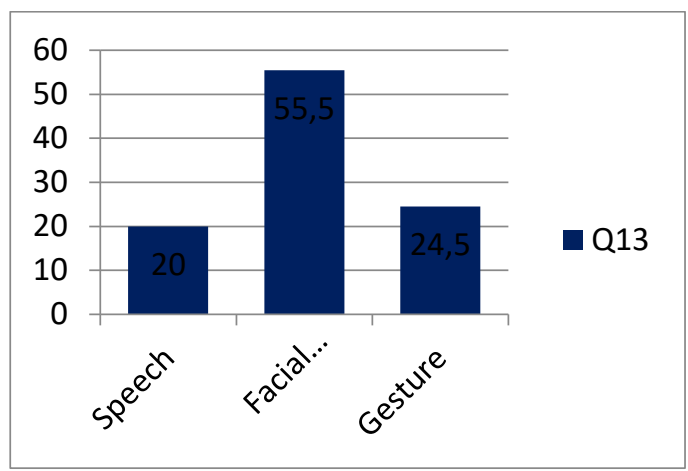

Figure 3. Do you know the teachers' mode from his/her

Question 13 asked about how the students know their teachers' mode? More than half of the respondents $(55.5 \%)$ answered from their facial expressions. The result is in line with Elfatihi(2006). As he stated the face is an outlet for individuals' feeling and teachers can hardly prevent their feelings from showing in their faces. As a result, teachers' facial expressions should be encouraging.

The fourth part of the questionnaire dealt with oculesics or eye contact. As stated by Elfatihi (2006) The first thing the teacher and students do before they start learning is eye contact. As a consequence, this eye contact exchange provides a context for subsequent communication. The questions in this part spin around some functions of eye-contact such as checking comprehension, increasing motivation by eye contact, frequency of eye contact and attitude of the students regarding eye contact.

Checking for understanding by asking directly "did you get it" does not see an appropriate way. Since the students either don't answer or they answer positively while really it is not the case. Thus, an effective way of checking to understand is by eye contact. 78.7 percent of the participants believe that they pay more attention to the lesson when the teacher make eye contact with them. They also don't like the teachers stare at them coldly. They also stated that their classmates avoid eye contacts with the teacher when they do not know the answers which are a kind of avoiding strategy. Furthermore, 43.1 percent of them agreed that teachers make eye contact only with talented students. 


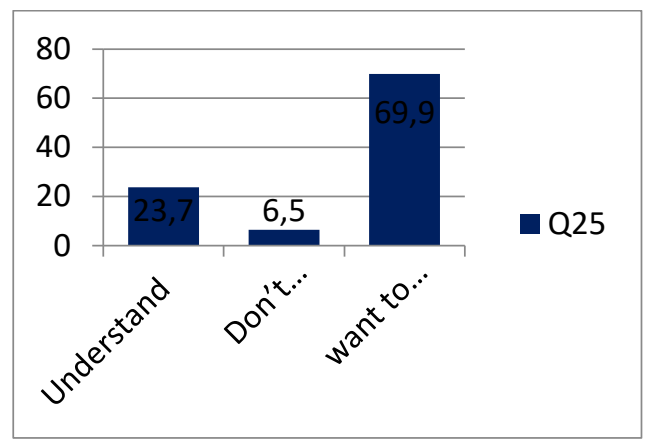

Figure 4. do you look at the teacher when you...

Eye contact can maintain the interest of the students. As it is clear from Figure 4, 69.9 percent of the respondents stated that when they want to understand they look at the teacher and only 6.5 percent of them mentioned that when they do not understand a point they look at the teacher may get the point better.

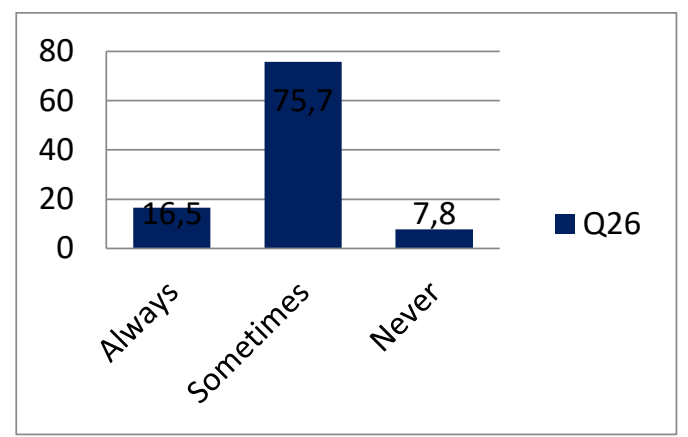

Figure 5. how often do you like the teacher to look at you?

However, eye contact should not be permanent to avoid embarrassment. This is also clear from the students' response to the frequency of eye contact between the teacher and them. From Figure 5 it is evident that 75.7 percent of the respondent likes the teacher to look at them sometimes and 16.5 percent like the teacher to look at them always.

Proxemics or territoriality as called by some researcher was the fifth part of the nonverbal communication questionnaire. Proxemics is the management of space socially as well as physically. In the classroom setting, physical management is of two types, i.e. students-student and teacher-student. In this study, aside from space or distance between students and teacher, privacy or personal distance was considered as a subpart of proxemics. The result of privacy will be explained in Table 2 in the ensuing part.

The participants $(82.1 \%)$ stated that they like to sit near the teacher and being close to the teacher does not disturb them. Also sitting in the first row will help them understand lessons better. They (70.4\%) like the teacher to move around the class 
because it makes them active. However, they do not like to be either too far or too near to the teacher.

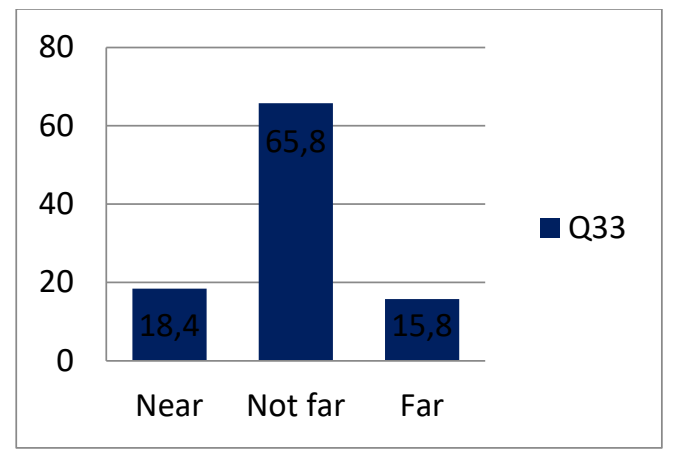

Figure 6. where do you like the teacher to stand from you?

Figure 6 illustrates the point that 65.8 percent of the students prefer sitting not far from the teacher in class.

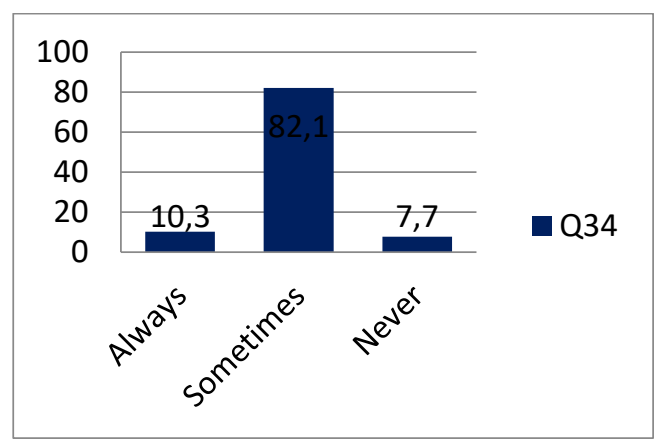

Figure 7. how often do you like the teacher to move around the class?

Furthermore, they do not like the teacher neither to move always nor to sit in one place all the time. Most of them (82.1) like the teacher move sometime in the class (Figure 7) due to the reason mentioned earlier such as making them an active and better understanding.

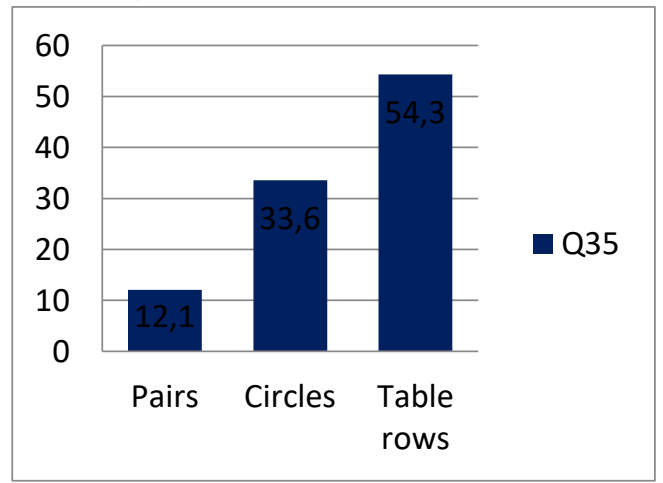

Figure 8. What sitting arrangement do you like? 
In the teaching-learning phase, the physical arrangement of the class is regarded an significant variable. Elfatihi(2006). Sitting for the final exam is different from sitting in a communication-based activity class. Figure 8 illustrates the point that more than half of the students (54.3) like the present table rows sitting while 33.3 percent of the students preferred sitting in the circle form in general English class and just 12.1 of them like sitting in pairs.

Vocalic was a subpart of paralanguage which was the sixth element of nonverbal communication of the questionnaire. Nearly 43 percent of the students agree that when the teacher speaks in a monotonous tone they and their classmates feel bored and 30 percent of them had no idea in this regard.

Chronemics was the seventh factor in the questionnaire, also known as temporary communication, about how individuals organize and use time (timing and time management).Nearly all of the students (93.7) like the teachers who come to class on time, give homework to them and spend more time with them.

Clothing conveys an significant message about who a individual is and what they can do. Artifacts are ornaments one display that holds communicative potentials. The age, ethnicity, status, role of socioeconomic class, group affiliation, character and more were conveyed by clothing and other decorations. The majority of the respondents (93.7\%) agreed with the idea that disheveled teacher is boring to see. Exactly 50 percent of them related intelligence to being attractive (Question 82). Even 51.0 percent of them mentioned that teachers hand watch is important for their friends.

Haptics and olfactics were the last two nonverbal communication factors in Table 2. Regarding haptics of the use of touch, they did not agree or disagree. 34.8 percent of the students felt that they will lose their stress by patting their back while 33.9 percent of them do not agree with this idea and interestingly 31.3 percent of them had no idea at all.

Finally, 81 percent of the respondents like their English teacher to use perfume and 12.1 percent of them had no idea.

The second part of the investigation was about privacy and private questions. It consists of nine subparts related to personal questions. The students were asked, "do they like English teacher ask these questions orally in general English class to be answered in English". The result of their opinion is shown in Table 2.

Table 2. percentages of answers to private questions

\begin{tabular}{lccc}
\hline \multicolumn{1}{c}{ Privacy } & Yes & No & No Idea \\
\hline personal description & 0.0 & 67.7 & 32.3 \\
\hline identification number & 6.8 & 53.4 & 39.8 \\
\hline Ethnicity & 35.4 & 39.8 & 24.8 \\
\hline Health & 9.7 & 61.9 & 28.3 \\
\hline
\end{tabular}




\begin{tabular}{llll}
\hline Financial & 17.7 & 52.2 & 30.1 \\
\hline Employment & 37.7 & 34.2 & 28.1 \\
\hline Criminal & 14.0 & 67.5 & 18.14 \\
\hline Life & 15.9 & 57.0 & 27.1 \\
\hline Education & 19.8 & 63.1 & 17.1 \\
\hline
\end{tabular}

It is interesting to see that not even a single person like to answer questions to the personal description such as age, weight, place, and date of birth or eye and hair color in front of other students. In other words, 67.7 percent of them disagreed to answer these questions and 32.3 percent had no idea.

The second part of privacy was about identification numbers such as debit or credit card. 53.4 percent of the participants answered negatively means they did not like to tell their insurance or debit card. Since they were students and not businessmen 39.8 percent of them also had no idea.

Students were not sensitive about asking ethnicity since all in the class were homogeneous and from one ethnicity, all white, Iranian and Persian as their mother tongue and English as a subject for them. As a result,the answers were not different and 35.4 percent agreed to answer the questions about race, color, and nationality and 39.8 percent disagreed, while 24.8 said no idea.

Asking about their health was the fourth part of the privacy questionnaire. In responding to the questions about mental or physical disability, 61.9 percent of the English students did not like to answer the questions. While 50.9 percent of them were eager to mention their blood type.

For answering the questions about finance such as income, a loan or spending habit more than half of the students (52.2\%) were not eager to answer.However, they were easy going to answer their parents' occupation and 37.7 percent expressed that they will answer these questions.

Asking criminal background questions was important for them. Table 2 showed that 67.5 percent of the participant did not like to answer.

They were also not eager to answer questions about their life such as their marital status, political and their beliefs in life. 60.5 percent did not like to reveal their marital status and 57percent were not eager to answer all the related questions in English class.

The last part of the privacy questions dealt with the educational background and their scores. Most of the respondent (63.1\%) did not like to answer the questions regarding their university scores or place graduation from school.

\section{Concluding remarks}

For effective interactions with others, both verbal and nonverbal communications are essential. For a classroom situation, non-verbal communication is not only crucial in 
daily communication, but equally important. NVC often provides much more meaning than people realize. In this study, the attitude of foreign language students about NVC had been reflected. IT was found that students like English teachers who illustrate and explain the subject for them,

The use of gesture while teaching which leads to a better understanding for them, are smiling, friendly, encouraging and kind, making eye contact with them frequently, timing and budgeting the class time for reviewing, and being well dressed and neat. But they do not like English teachers who are cold and hopeless, use monotonous tone while teaching and are serious.

The instinct to secure space for oneself and to defend that space against potential intruders is one of the most shared aspects between humans and animals. The social anthropologist Edward Hall was the first one who coined the term proxemics or spatial separation. People's sense of territoriality becomes evidence in some places like an elevator. As it is stated by Elfatihi (2006), Researchers noted that when one or two individuals are in the elevator, they lean against the elevator wall, when there are four, they occupy the four corners of the room, and when there are five or six, they turn to face the door, standing tall and thin.

As all human beings have right, students also have privacy right. The students do not like to answer questions regarding their personal description, identity ethnicity mental or physical disability, family employment Political affiliation and belief, marital status and score, and educational background.

Regarding the last part above one should mention that in America, under numerous federal legislation, students are given multiple freedoms, including the privacy of their academic documents. The 1974 Family Educational Rights and Privacy Act (FERPA) is a federal law adopted to enable learners to access their instructional documents while restricting others ' capacity to access those documents, except as otherwise permitted by law. (Van Dusen \& Spies, 2003).

Thus, it is recommended that English teachers do not ask questions which violate students' privacy, especially in English classes. With the aim of communication raising the topics to be discussed in front of other students can be problematic for learners. In this way, their ability to communicate also cannot be evaluated since if they do not answer teachers can't get that it is due to lack of knowledge or unwillingness. Instead, teachers can encourage learners to disclose private data, faith and intimate feelings in the classroom instead of requiring them (Davis, 2001). Even schools should be careful about the privacy of students as Early (2004) stated schools may legally disclose certain student data even in delicate circumstances, but they must follow the laws of privacy closely.

As every research has its limitation this study also is not an exception. This research was performed in one university and with a restricted amount of respondents, other researchers can expand the research to find a better result. 


\section{References}

Allen, L. Q. (2000). Nonverbal accommodation in foreign language teacher talk. Applied Language Learning, 11, 155-176.

Batmang, B., Gunawan, F., Abdul Samad, I., \& Shamsuri Md Saad, M. (2018). The Influence of Lecturers' Language Style toward Higher Students' Psychological Condition in Indonesia. In Arab World English Journal (Vol. 9). https://doi.org/10.24093/awej/vol9no4.15

Birk, B. J. K. T. (1990). Nonverbal behaviours, persuasion, and credibility. Human Communication Research, 17, 140-169.

Christopher, E. (2002). Gender differences in nonverbal behavior. Retrieved from http//www.qnslem.edu/internet/psych/theses/seniors2002/Christopher/webpage. html

Dam, S. (2005). Aspects of nonverbal communication. The Internet TESL Journal. Retrieved from iteslj.org

Davis, A. (2001). Do children have privacy rights in the classroom? Studies in Philosophy and Education, 20, 245-254.

Development, S. (2006). The role of nonverbal communication in Beginners ' EFL Classrooms By: Mohamed ELFATIHI. 2005-2006.

Early, F. (2004). Where do student privacy laws leave schools? The Education Digest, $69,18-22$.

Edward T. Hall. (1959). The Silent Language. New York: Doubleday.

Feyereisen, P. (2007). Fernando Poyatos (2002). Nonverbal communication across disciplines. Volume 1: Culture, sensory interaction, speech, conversation. Volume 2: Paralanguage, kinesics, silence, personal and environmental interaction. Volume 3: Narrative literature, theater,. Gesture, 6(2), 273-282. https://doi.org/10.1075/gest.6.2.11fey

Gregersen, T. S. (2007). Language learning beyond words: Incorporating body language into classroom activates. Reflections on English Language Teaching, 6(1), 51-64. 
Hassan, M. M. T. (2007). Non verbal communication: The language of motivation for Pakistani students. Journal of Language in India, 7, 32-43.

Johns, S., \& Lawson, K. (2005). University undergraduate students and library-related privacy issues. Library and Information Science Research, 27(4), 485-495. https://doi.org/10.1016/j.lisr.2005.08.006

Karimi, M., Dabaghi, A., \& Tabatabai, O. (2012). The impact of nonverbal communication on Iranian young EFL learners' attitude and understanding of lexical items. BELT, 3(2), 188-203.

Kellog P, L. B. (1993). Envoy, Your Personal Guide to Classroom Management. Battle Ground: Michael Grinder.

Kruger, F. (n.d.). The use of nonverbal communication in the foreign language classroom: A pilot study. Retrieved from http://www.tesolreview.org/down/4. Frans Kruger.pdf

Kusanagi, Y. (2004). Analysis of research on nonverbal communication in language education. 382-494. JALT.

Leathers, D. G. (1997). Successful Nonverbal Communication: Principles and Applications. Needham Heights: Allyn and Bacon.

Mainez, I. (2017). Grado en Educación Primaria " NONVERBAL COMMUNICATION IN ENGLISH AS A SECOND LANGUAGE .”

Mata, L. (2010). The psychological dimensions of privacy and the school success. Economy Transdisiplinarity Cognition, XIII(2), 70-79.

Negi, J. S. (2009). The Role of Teachers' Non-Verbal file:///D:/vision/azedahcommunication/batmang.pdf in ELT Classroom. Journal of NELTA, 1(1), 101110. https://doi.org/10.3126/nelta.v14i1.3096

Nobrega, D. (2012). Students' spontaneous smile in the EFL classroom. Acta Scientiarum. Language and Culture, 34(2), 233-240.

Safarali Karbalai, S., \& Hamidi, H. (2012). The impact of videos presenting speakers' gestures and facial clues on Iranian EFL learners' listening comprehension. International Journal of Applied Linguistics \& English Literatur, 6(12), 106-114. Santos, M. (n.d.). Contribuições dos Aspectos Não-Verbais e Verbais ao Discurso de 
25 | VISION: JOURNAL FOR LANGUAGE AND FOREIGN LANGUAGE LEARNING

Sala de Aula. Universidade Federal de Alagoas, 6.

Van Dusen, V., \& Spies, A. (2003). Student Privacy: Implications for Pharmaceutical Education. American Journal of Pharmaceutical Education, 67(1), 8. https://doi.org/10.5688/aj670108

Warkentin, M., Johnston, A. C., \& Shropshire, J. (2011). The influence of the informal social learning environment on information privacy policy compliance efficacy and intention. European Journal of Information Systems, 20(3), 267-284. https://doi.org/10.1057/ejis.2010.72 